\title{
Transdisciplinary Research on Sustainability in Europe conference discuss funding mechanism recommendations for the European Commission
}

\author{
Andrew Barton
}

Envigogika 2013/VIII/2- Informace/ Information

Publikováno/Published 06 09. 2013

\section{DOI: http://dx.doi.org/10.14712/18023061.379}

Modify funding guidelines to facilitate greater transdisciplinary research for sustainable development. That was the message to the European Commission made loud and clear by academic and NGO sustainable development practitioners in Prague recently as a result of a Transdisciplinary Research on Sustainability (TDRS) in Europe conference held on 23 and 24 May.

The conference, organised by the Charles University Environment Center (CUEC) together with the Schumacher Institute for Sustainable Systems, based in Bristol, the United Kingdom, aimed to help inform the EU's research agendas and meta-agendas about the evaluation, conduct and processes of TDRS with information, perspectives and analyses from practitioners. It also successfully sought to discuss and develop recommendations to the European Research Area in the run-up to the introduction of the new Horizon 2020 - the EU funding instrument for innovation and research - to help enable better and more productive TDRS.

The motivation behind the conference was the call being issued by major EU research programmes for transdisciplinary research to address 'wicked' joined up and complex problems - particularly in the area of sustainability. Whilst there is an emphasis on the dissemination of substantive results from funded projects, there is less attention paid to the sharing of the experiences and lessons learnt from the project processes, problems and issues, and strategies developed for dealing with these. This conference provided an opportunity to share and reflect on issues of TDRS, including methodology and management, together with an opportunity to contribute to recommendations to the ERA for the further development of research capacity on TDRS.

A colourful and wide range of academics and NGO practitioners were assembled at the conference representing a wide spectrum of European Union states and the odd non-EU state with a diverse mix of backgrounds, albeit all interested in sustainability and how to create greater traction for the concept across Europe via transdisciplinary research. To this end, it was vital to address the European Commission directly and the conference organisers were grateful to have Lino Paula from the EC's DG Research present. Lino set the tone for the conference by in his opening presentation on the issue of Transdisciplinarity, Responsibility and Horizon 2020. This was followed up with a talk from Dr Maik Adomssent from Leuphana University of Lueneburg on the researcher perspective of TDRS, and a presentation by Dr Jan Frouz of Charles University on managing transdisciplinary consortia. Other key note presentations included a discussion led by Ian Roderick of the Schumacher Institute on what 
exactly a 'global wicked problem' is, and Dr Jenneth Parker, also from the Schumacher Institute on degrees of interdisciplinarity and the difference they make. A final key note presentation was made on the morning of the second day by Sándor Fülöp, the former Hungarian Commissioner for Future Generations on future generations as key research stakeholders in all TDRS calls.

Apart from the usual question and answer session at the end of each key note presentation, conference participants also had the opportunity to present posters and deliver a short 5-minute description about them. These ranged in theme from TDRS in post-socialist European states, the pre-requisites and processes and outcomes of interdisciplinary teaching, and relationships between systems modelling and scenario development in TDRS, to transdisciplinary participatory action research, and equity and sustainability to TDRS from the perspective of an early career researcher.

A final day workshop was spent enumerating the research policy recommendations that arose out of the conference discussions for eventual presentation to the DG Research at the European Commission. The final day also involved an interesting panel discussion on the subject of academic freedom, and 'corruption' or rather ethics in research and education which provided the basis for the future development of research questions into this area which the conference organisers plan to follow up on.

Individual presentations and posters can be accessed here: http://mosur.czp.cuni.cz/index.php/en/events/conferences/101-transdisciplinary-researchon-sustainability-in-europe-conference-outputs 